\title{
Planning biomass energy production in a farming area
}

\author{
G. Fiorese ${ }^{1,2}$, E. Cozzolino ${ }^{3}$, G. Guariso ${ }^{1}$, G. Paris $^{2}$ \\ ${ }^{1}$ Dept. of Electronics and Information \\ Politecnico di Milano \\ via Ponzio 34/5, 20134 Milano \\ Phone/Fax number: +0039 022399 9630/9611, e-mail: fiorese, guariso@elet.polimi.it \\ ${ }^{2}$ LEAP Laboratorio Energia \& Ambiente Piacenza \\ via Nino Bixio 27, 29100 Piacenza (PC) \\ Phone/Fax number: +0039 052335 6879/6884, e-mail: gianmarco.paris@gmail.com \\ ${ }^{3} \mathrm{CRPV}$ Centro Ricerche Produzioni Vegetali \\ via dell'Arrigoni 120, 47522 Cesena (FC) \\ Phone/Fax number: +0039 054731 3511/7246, e-mail: eugenio.cozzolino@tin.it
}

\begin{abstract}
A thorough analysis of biomass supply and of energy demand should be carried out at local scale in order to optimize bioenergy plans and deal with the related social ad environmental issues. We present a method to identify the optimal use of biomass: local biomass availability is assessed, the road network is used to evaluate transportation costs, and different energy conversion technologies are considered. Energy crops and animal slurries are considered as feedstocks. We also estimate the amount of land available for energy crops, given the current land use. The comparison between possible conversion systems is carried out solving an optimization problem for the net energy produced in the system, accounting for energy needs for biomass cultivation, collection, and transportation. An emissive indicator is used to evaluate the amount of carbon equivalent emissions avoided. The economic performance of the systems is also analysed. The method is applied to the province of Ravenna in Italy. Transport and cultivation energy and emissions are much smaller than the energy produced or the emissions avoided. The biomass transformation chain can indeed provide $1.9-3.3 \%$ of the present power consumption and may reduce GHG emissions by $1-3.5 \%$ by replacing fossil fuels.
\end{abstract}

\section{Key words}

Biomass supply chain, energy crops, land use planning, cogeneration, biogas.

\section{Introduction}

Bioenergy exploitation plans are usually considered to be environmentally acceptable because they provide renewable sources of energy with low greenhouse gas emissions. However, as for any energy project, they can also have non-negligible local impacts. It is thus necessary to clearly identify all the issues to deal with when project developers, stakeholders, decision makers and investors discuss together about the viability of a proposal:

1) What types and amounts of biomass resources are available or can be produced sustainably?
2) Are there competing uses for this biomass and/or would its use for energy purposes impact on other activities?

3) What suitable supply chain and conversion technologies are available that will enable environmentally acceptable bioenergy products and energy carriers to be generated efficiently?

4) What impacts will the increasing use of biomass in a region have on the local environment and, particularly, on water supplies?

5) Will beneficial social issues result, such as employment, rural development, social cohesion, and climate change mitigation?

The choice between different supply chains and conversion technologies depends on the type, distribution, and amount of available biomass and on the form and location of the final energy demand (see e.g., [1]) and should be accompanied by the evaluation of environmental (e.g., emissions), economic (e.g., return on investment) and logistics (e.g., secure feedstock biomass) issues. The overall task is very complex and thus it is useful to develop tools that enable decision makers to compare different alternatives and to support the choice of the best bioenergy systems.

\section{Methods}

In this paper we describe one such method to assess and evaluate different biomass-to-energy systems at local scale over a defined territory, in order to ensure sustainable biomass exploitation over time, both from the economic and the ecological points of view. As a first step in this direction, it is necessary to assess the biomass potential of the studied area on the basis of residues, byproducts and dedicated energy crops. According to the local socio-economical context, feasible conversion technologies should be identified in order to meet the local demand of energy in the form needed (electricity, 
heat, liquid fuel or biogas). In particular, in many countries, it is essential to consider that land is a scarce resource and both the farming of dedicated bio-energy crops and the installation of conversion plants may conflict with other established land uses [2].

It is necessary to assess if the available biomass can ensure the feedstock supply of the plant for all of its useful lifetime at a reasonable distance from the plant (for instance, in Italy recent legislation aims at subsidizing plants that collect biomass feedstock within a maximum distance of $70 \mathrm{~km}$, even though the law has not yet become in force). Therefore the analysis is divided into two parts: the first aims at assessing biomass availability, including land for dedicated energy crops, and the second at comparing and evaluating different plant networks and conversion technologies, given the available biomass.

The process of selecting available land for dedicated crops should start from the analysis of the land use map and follows the method presented in [3]. We define a set of constraints in order to determine the possibility to grow energy crops only on areas that are both available and suitable. The following constraints were defined:

- Geomorphologic: we consider unsuitable land with slope greater than $20 \%$ and altitude higher than 700 m a.s.l.;

- Established land use for agricultural crops: this cropland can be considered unsuitable because the soils would not be immediately available and/or because it represents an inalienable local resource (e.g., fruit cultivations are extremely valuable in the study area presented later and thus have been considered not available);

- Naturalistic: we exclude protected areas, dunes, wetlands, primary and secondary ecological corridors, ecological nets, re-balancing of ecological zones, parks, SIC (Site of Community Importance), ZPS (Special Protection Areas), and RAMSAR zones;

- Soil vocation: based on the pedological map of several important parameters (salinity, $\mathrm{pH}$, limestone, water retention capacity, etc...), we identify areas that can be used for each energy crop;

- Climatic (temperature, precipitation and their interaction with soils): we exclude areas were climate and precipitation are not sufficient for crop growth without massive use of agricultural inputs;

- Dimensional: we define a minimum dimension of the allotment of 30 hectares, because of the difficulties to obtain significant earning performances in smaller parcels of lands;

- Good Agricultural Practices: we assume a quadrennial rotation of energy crops with food crops with the aim of meeting the European Biomass Action Plan and the Nitrates Directive requirements [1]. This means that only one fourth of the dedicated land will be cultivated every year with energy crops.

In principle, one can formulate a very general mathematical programming problem that, considering all the above constraints, tries to determine the type of biomass, together with the best suited conversion technologies, the optimal number and location of plants, and the relative collection basins, i.e. all the parcels that convey their biomass to the same conversion plant.

However, such a general formulation is not only very complex from the mathematical viewpoint, but can determine solutions that may not be accepted in practice, for instance for the uneven distribution of benefits and costs. The standard approach followed in the literature is thus to analyse separately alternative scenarios for different kinds of biomass and the related specific conversion technologies.

Such a mathematical problem also requires selecting a certain perspective and thus the definition of one or few objective function(s) to be optimized. For example, in order to assess if the bio-energy system contributes to the reduction of fossil fuel dependency, the objective function should evaluate the energy flows involved in the whole process, from growing and harvesting biomass (e.g., energy needed for farm machinery and for fertilizers), to transport (fuel for the trucks) to the final end-use. An alternative formulation may entail the minimization of the carbon dioxide emission from the complete energy system, or the more classical economic approach of maximizing the net present value of the plan. Whatever the objective, if the biomass availability in each parcel, the road network, and the logistic costs in the area under examination are assumed to be known, the optimization problem can be solved relatively easily to determine the number and location of conversion plants, and their respective energy districts, i.e. all those parcels that convey their biomass to the same conversion plant.

Such problems are known in the literature as locationallocation problems and have been applied to many different cases [4].

If alternative scenarios are analysed, it is then necessary to compare and rank them to decide which are best to be pursued. Note that not all the alternatives are mutually exclusive. For example, if one considers biogas production from zootechnical residues and the combustion of crop residues, there is no competition for land because of the different sources of the feedstock. On the contrary, the production of silage maize for anaerobic digestion may compete for land with poplars for combustion. The comparison and final choice between the various alternatives may require a strong involvement and in-depth discussion of decision makers and stakeholders.

To support this phase, two issues, economic viability and greenhouse gases emissions, besides energy are of major importance. Benefits and cost and avoided emissions ( $\mathrm{t}$ $\mathrm{CO}_{2}$ equivalent that would not be emitted by substituting bioenergy to fossil fuels), are also associated to each step of the biomass exploitation chain. They must be both as high as possible, but the latter is becoming more and more relevant due to increased attention to global climate changes and related policies. Several models have indeed been developed to estimate the flows of carbon and other emissions associated to the production of energy form biomass (e.g. [5]).

The final optimal plants location problem must also include the specific features of both the territory and the 
transformation plants. For instance, parcels candidate to house a plant should have enough land available for its installation and the possibility of absorbing the electric and/or thermal energy produced.

For a fixed biomass-technology scenario, the optimization problem is formulated using two sets of decision variables: $x_{i j}$ represents the fraction of available biomass that is hauled from municipality $i$ to plant $j$ at a distance $d_{i j}$ (derived from the current road network); and $y_{j}$ is a binary variable that is 1 if a plant is active in municipality $j$ and 0 otherwise. The net energy production (MJ/yr), to be maximized, can be written as follows:

$$
\begin{aligned}
\max _{\left\{x_{i j}, y_{j}\right\}} J & =\sum_{i} \sum_{j}\left[\left(\eta_{j} \cdot L H V \cdot b_{i} \cdot x_{i j}\right)+\right. \\
& \left.-\left(\text { en }_{\text {transport }} \cdot d_{i j} \cdot b_{i} \cdot x_{i j}\right)-\left(e n_{\text {crop }} \cdot b_{i} \cdot x_{i j}\right)\right]
\end{aligned}
$$

where: $b_{i}$ is the biomass available, in dry tons/ha, in municipality $i$; $\eta_{j}$ is the $j$-th plant efficiency; $L H V$ is the lower heating value, in MJ/dry ton; en transport is the energy, in $\mathrm{MJ} / \mathrm{dry}$ ton $/ \mathrm{km}$, for hauling a unit of biomass over a unit of distance, return trip included; $e n_{\text {crop }}$ is the annual energy, in $\mathrm{MJ} / \mathrm{dry}$ ton, for growing and harvesting the biomass. All these values are known once the biomass type is selected.

The objective function is subject to the following constraints:

$$
\begin{aligned}
& \underline{C A P}_{j} \cdot y_{j} \leq \sum_{i} L H V \cdot b_{i} \cdot x_{i j} \leq \overline{C A P}_{j} \cdot y_{j} \quad \forall j \\
& x_{i j} \leq y_{j} \quad \forall i, j \\
& \eta_{j} \sum_{i} L H V \cdot b_{i} \cdot x_{i j} \leq D_{j} \quad \forall j \\
& x_{i j} \geq 0, y_{j}=0,1 \quad \forall i, j
\end{aligned}
$$

The first set of constraints (2) limits the supply to each plant in a range, defined by a lower and a upper bound of the production capacity (in $\mathrm{MJ} / \mathrm{yr}$ ), when the plant is actually built in location $j\left(y_{j}=1\right)$, and sets the supply to zero otherwise $\left(y_{j}=0\right)$. The second constraints (3) define that the biomass can be hauled only to an active plant, while the third set (4) guarantees that the energy produced at the $j$-th plant can be accommodated by the local electrical or thermal demand $D_{j}$. It is interesting to note that setting the upper bound $\overline{C A P}$, one may strongly influence the structure of the optimal solution: setting it to high values allows centralized solution with few plants and large collecting districts, while low values force a more distributed production system.

The resulting mixed integer linear programming problem can be solved using one of the many packages available. In the following case study, What's Best [6], an Excel add-in for linear, nonlinear, and integer modelling and optimization has been used. For a more detailed formulation of the objectives of the decision problem, refer to [3].

\section{A case study: Ravenna province}

The proposed method has been applied to the province of Ravenna, located in the Emilia-Romagna Region in Italy. The extension of the district, composed of 18 municipalities, is $1,858 \mathrm{~km}^{2}$. The western side of the area (about $20 \%$ of the extension) is mountainous because of the Apennines, but most of the district lays in a fertile plain. The total agricultural area equals $77 \%$ of the overall district, $82 \%$ of which is dedicated to crops.

For the province of Ravenna, we estimated the amount of biomass from current zootechnical residues and from potential energy crops. Specifically, we assessed the amount of land available and suitable for a limited number of usable crops: miscanthus (Miscanthus $x$ giganteus), poplar (Populus spp.), robinia (Robinia spp.), maize (Zea mais), sorghum (Sorghum).

The soil selection process led to the identification of 9,722 hectares of available and suitable soils (corresponding to $8.3 \%$ of the agricultural area in the province). The potential biomass availability for the selected set of crops is shown in Table I. Of course each crop must be considered alternative to the others. Figure 1 shows the land available for energy crops: all areas in white are either not available or not suitable. Areas in green are available and the darker the shade, the more suitable for the selected crop.

Table I. - Potential biomass availability

\begin{tabular}{|l|c|c|}
\hline Energy crop & $\begin{array}{c}\text { Preferred biomass-to- } \\
\text { energy system }\end{array}$ & $\begin{array}{c}\text { Potential biomass } \\
\text { (dry kt/year) }\end{array}$ \\
\hline Miscanthus & heat/power & 114.5 \\
\hline Poplar & heat/power & 95.4 \\
\hline Robinia & heat/power & 70.0 \\
\hline Maize silage & biogas & 159.0 \\
\hline Sorghum & biogas & 171.8 \\
\hline
\end{tabular}

As for biomass from residues, we consider only animal slurry (not animal manure, which is mostly used for soil fertility reintegration) because it can be easily coprocessed with herbaceous biomasses (e.g., silage maize or sorghum) in anaerobic digesters. The amount of animal slurry that is available in the province was estimated in [7] to be around 670,000 wet t/year of pigs' slurry and 80,000 wet t/year of livestock slurry.

We analysed two energy conversion technologies. The first is a cogeneration plant for the joint production of electricity (for the national electricity grid) and heat (for a district heating network). The cogeneration plants considered is an Organic Rankine Cycle (ORC) for small capacities (8 MWt heat and 1.1 MWe electricity, coupled with two water boilers fed by biomass of $6 \mathrm{MW}$ each [8]); several plants of this type are active in Italy, Austria and other countries. For larger capacities, we considered conventional combined cycles plants. The second technology is anaerobic digestion to produce biogas, which is then fed into small CHP engines mainly for the production of electricity. In these anaerobic digesters, animal slurry is co-processed with sorghum (20\% of the slurry as input).

Five alternative bioenergy systems have been considered for the case of Ravenna:

1) The use of poplar in cogeneration plants distributed over the area of the province,

2) The use of poplar in one centralized cogeneration plant supplied with all available biomass, 
3) The use of giant reed in cogeneration plants distributed over the area of the province,

4) The use of giant reed in one central cogeneration plant,

5) The co-digestion of animal slurry with sorghum in small anaerobic digestion plants distributed over the area of the province.

Poplar was preferred to robinia and sorghum to maize because of the higher yields.

The location of the plants is given by the resolution of the optimisation problem described in the "Methods" section with the objective of maximizing the net energy production. Parameters are listed in Table II. Similar problems and resolutions can be found in the literature, e.g., [9], [10].

For alternatives 2 and 4, the cogeneration plant is assumed sited in the vicinity of the city of Ravenna, which has a sufficient heat demand to satisfy the related constraint on heat production. The solution of the optimization program is however interesting to define the supply basin: far parcels may have a negative energy balance and thus may not belong to the optimal solution. Finally, for alternative 5, it has been assumed to site one anaerobic digester coupled with a CHP engine in each municipality; each of these plants is dimensioned to be fed with the biomass (slurry and sorghum) available in the same municipality. Again, some municipality may not have enough biomass to justify the presence of a plant even of the smallest feasible size. The emissive and economic performances of all the alternative scenarios where also evaluated through the indicators described in the "Methods" section.

Table II. - Parameters used for the energy optimization problem, the emissive indicators, the economic discussion.

\begin{tabular}{|c|c|}
\hline Parameter & Value \\
\hline Energy of transportation & $1.01863 \mathrm{MJ} / \mathrm{km} /$ wet t \\
\hline Emission of transportation & $71.8 \mathrm{~g} \mathrm{CO}_{2} / \mathrm{km} /$ wet t \\
\hline Cost of transportation & $0.034 € / \mathrm{km} /$ wet t \\
\hline Energy for poplar cultivation & $540 \mathrm{MJ} / \mathrm{dry} \mathrm{t}$ \\
\hline Energy for giant reed and sorghum & 1,153 MJ/dry t \\
\hline Emission of poplar cultivation & $0.064 \mathrm{~kg} \mathrm{CO} 2 /$ dry t \\
\hline Emission of giant reed and sorghum & $0.374 \mathrm{~kg} \mathrm{CO} /$ dry t \\
\hline Cost of poplar, giant reed & $70 € /$ wet $t$ \\
\hline Cost of sorghum & $30 € /$ wet $t$ \\
\hline Cost of ash disposal & $50 € / t$ of ash \\
\hline Electrical and thermal efficie & \\
\hline - Cogeneration plants & $0.17 ; 0.80$ \\
\hline - Biogas plants & $0.37-0.40 ; 0.44$ \\
\hline - Natural gas plants & $0.39 ; 0.80$ \\
\hline Emission factor of avoided natural $g$ & $54.9 \mathrm{~g} \mathrm{CO}_{2} / \mathrm{MJ}$ \\
\hline
\end{tabular}

\section{Results}

The results of the energy objective, of the indicators and of the plant location for the five alternatives are described in the following. In alternatives 1 and 2, the poplar gives about 95 thousand dry t of biomass per year. With this availability, five cogeneration plants of the quoted standard size are fed in alternative 1 . Their optimal locations are in the municipalities of Alfonsine, Conselice, Faenza, and two plants in Ravenna (as shown in Figure 1). In alternative 2, the unique plant, analogous in capacity to the sum of the five plants, is located in the municipality of Ravenna and its collection basin covers the entire province.

In alternatives 3 and 4, the giant reed, thanks to its high yield, produces about 159 thousand dry t of biomass per year. This amount of biomass allows feeding nine standard plants located by the solution of the optimisation problem in the municipalities of Alfonsine, Cervia, Conselice, Faenza, Lugo, Massalombarda, two plants in Ravenna, Russi. The fact that five coincide with those determined by alternative 1 is particularly interesting from the decision point of view: the selected locations are robust to a possible change of the type of feedstock. Again the entire province is utilized to supply a unique larger plant located in the municipality of Ravenna in alternative 4 .

In alternative 5, it is assumed that all 686 thousand wet tons of slurry are co-processed together with 112,000 dry $\mathrm{t}$ of sorghum (note that not all sorghum is used because only $20 \%$ of the wet input has to come from herbaceous sources). The size of the plants varies from municipality to municipality according to the local slurry availability. The CHP engines coupled to the anaerobic digesters range from a minimum of $190 \mathrm{kWe}$ to a maximum of 1.83 MWe.

The energy performance of the five alternatives is showed in Table III. The highest value of the net energy produced, considering both electric and thermal energy, is reached by alternative 5 . This is due to the high availability of slurry and of sorghum. Driven by the high availability of biomass from giant reed, alternatives 3 and 4 are second and third best with respect to net energy production. If, on the other hand, we look only at the production of electric energy, alternatives 3 and 4 are those that produce the highest amount. Electricity consumption in the province in 2007 was 2976.4 GWh [11]; energy from biomass would thus substitute between 1.87 and $3.29 \%$ of 2007 electric consumption. Finally, from Table III it is possible to observe that the energy cost of transport is significantly smaller than the production of energy. On the other hand, the energy for dedicated crops cultivation is quite higher; however, the increased energy input necessary for the cultivation of the giant reed (about three times higher than for the poplar) is outclassed by the increase in the energy produced.

The results of the emissive indicator are also shown in Table III. Alternatives 3 and 4 obtain similar values of the indicator, which is the highest with respect to the other alternatives. These two alternatives are those that allow the highest production of electrical energy and this, in turns, allows avoiding a larger amount of emissions with respect to the other alternatives. In alternatives 3 and 4 the reduction of GHG emission represent $2 \%$ of those due the primary energy consumption of the province (much of it destined to export) and 3.4\% of the province final consumption. This difference is due to the fact that the province is en exporter of electric energy to the rest the country: in fact, there are two plants with a total capacity of $200 \mathrm{MW}$. The per capita $\mathrm{CO}_{2}$ emission thus considerably changes (from 21,1 to 12,6 ton of $\mathrm{CO}_{2}$ ) [12], if one considers the primary energy or the final energy consumption. In any case, the possible reduction almost corresponds to the satisfaction of the Kyoto commitment, if one considers that the required reduction 
for Italy is $6.5 \%$ with respect to the quite lower 1990 emissions.

Table III also lists the contribution of all terms to the net amount of avoided emissions: the avoided emissions due to the production of electrical and thermal energy (not considering auto-consumption), those due to the transport of biomass (both from the municipality of origin to the plant and within each municipality) and emissions due to the cultivation of the energy crops. Values in the table show that new emissions due to transport and to crop cultivation are orders of magnitude lower than the avoided emissions.

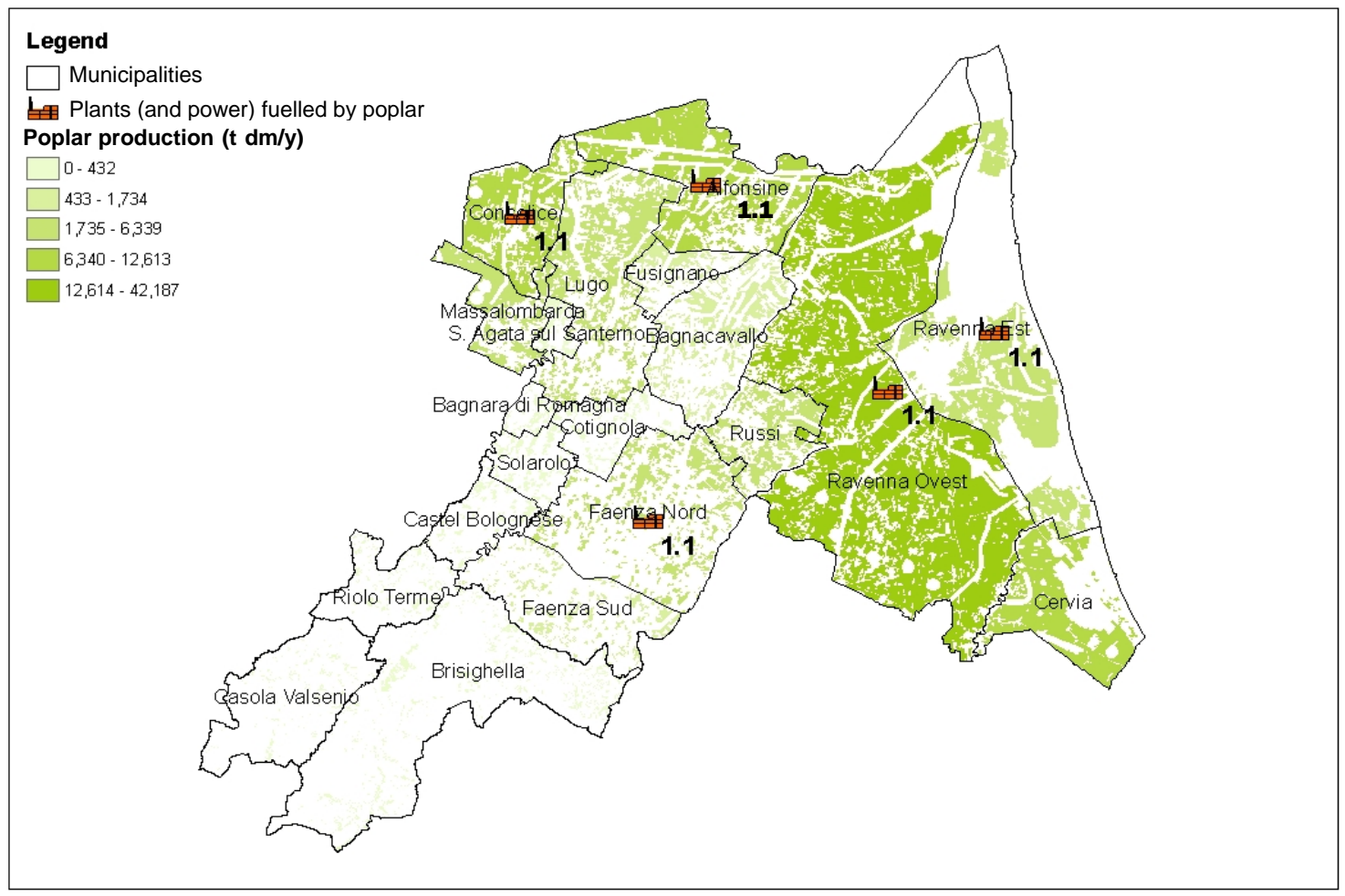

Fig. 1. Availability of biomass from the cultivation of poplar and location of five conversion plants.

\section{Economic evaluations}

Analyses of the economic performance of the five alternatives have been carried out by assessing the net present value, as it is customary for planning decisions. The initial investment for the standard 1.1 MWe cogeneration plant (alt. 1 and 3) is estimated to about 30 M€ [8], accounting for both the plant and the heat distribution network, which is responsible for about one third of the overall investment. This estimate derives from the experience of a few plants of this kind in Northern Italy. The cost of the plant can be determined, with good approximation, once that the technology and the capacity have been set; however, the same is not true for the heat distribution network. Its cost, in fact, can vary a lot according to specific characteristics of the local urban area that influence the length of the network and the digging. The same considerations are valid for the larger cogeneration plant (alt. 2 and 4), whose initial investment has been estimated from the literature [13].

The cost of operation and management of the plant, the purchase and the transport costs of the biomass and the cost of the disposal of the remaining ashes (Table II) were all accounted for in the NPV. The revenues from the thermal and electric energy sold to the market have been considered together, both with and without national incentives for the use of renewable energy resources.

The NPV is positive for all alternatives and the payback time is always shorter than 10 years. However, incentives significantly contribute to these promising economic performances: without any form of incentive the payback time increases for all alternatives, for example, up to 16 years for alternative 1 and 3 .

For alternative 5, the analogous flows of costs and revenues have been computed, with the initial investment considered a slightly non-linear function of the digester capacity according to data in the literature [9]. These systems produce much more electric energy than thermal energy (Table III), therefore the presence of incentives, that in Italy reward only electric energy, are critical for the economic profitability of the system. In fact, the payback time is about 6 years with incentives, but without incentives the assumed 20 years of life time are not enough to repay the investment.

\section{Conclusions}

We can conclude observing that all the objectives and indicators assume positive and high values and therefore that all the systems considered in the 5 alternatives produce energy, save $\mathrm{CO}_{2 \mathrm{eq}}$ emissions and are economically sustainable. It is possible to substitute between 1.9 and $3.3 \%$ of the electric energy consumed in the province and presently produced from fossil fuels; more fossil fuels are saved when jointly producing electric energy and heat, to be distributed through a district heating systems. The use of biomass allows reducing $\mathrm{CO}_{2 \text { eq }}$ emissions in the atmosphere as well between 1 and 3.5\%.

Several other social and environmental issues drive the choice of a biomass-to-energy system. For instance, the anaerobic digestion chain may be essential in areas with 
abundant animal slurry or manure, since they can emit methane, if untreated, that has a global warming potential 21 times higher than carbon dioxide. Biomass-to-energy systems that exploit dedicated cultivation to obtain biomass may differ because herbaceous, annual crops, such as sorghum, may have a higher production rate than poplar (arboreous) but, on the other hand, fossil fuel, GHG's emissions and the energy necessary to their cultivation are higher than for poplar cultivation. The key point is however, that arboreous crops require a longer term investments, since land must be dedicated to poplars for some 10-15 years, while herbaceous crops may be changed every year, following more closely the evolution of demand. Cogeneration plants have a higher energy return, but must be built close enough to urban centres to exploit their thermal energy production, which may not be easily accepted by citizens in the vicinity.

It is clear that not all the possible combinations of biomass, technology, location, and energy final form can be investigated, but the purpose of these studies is just to offer a sound and documented analysis of the most significant alternatives. Probably the most acceptable solution is represented by a mix of "centralized" and "distributed" uses/solutions and a mix of residues and dedicated crops that explicitly accounts for the specific features of each subarea in the province.

Table III. - Results

\begin{tabular}{|c|c|c|c|c|c|c|}
\hline & & $\begin{array}{l}\text { Poplar } \\
\text { distributed } \\
\text { alt } 1\end{array}$ & $\begin{array}{c}\text { Poplar } \\
\text { concentrated } \\
\text { alt } 2\end{array}$ & $\begin{array}{c}\text { Giant reed } \\
\text { distributed } \\
\text { alt } 3\end{array}$ & $\begin{array}{l}\text { Giant reed } \\
\text { concetrated } \\
\text { alt } 4\end{array}$ & $\begin{array}{l}\text { Sorghum } \\
\text { and manure } \\
\text { alt } 5\end{array}$ \\
\hline Biomass from energy crops & $\mathrm{d} \mathrm{kt} / \mathrm{yr}$ & 90.3 & 95.3 & 157.5 & 159.0 & 112.3 \\
\hline Animal manure & w kt/yr & - & - & - & - & 686.7 \\
\hline Number of plants & & 5 & 1 & 9 & 1 & 16 \\
\hline \multicolumn{7}{|l|}{ Energy objective } \\
\hline Electric energy production & $\mathrm{TJ} / \mathrm{yr}$ & 200.1 & 211.3 & 348.9 & 352.1 & 285.8 \\
\hline Thermal energy production & $\mathrm{TJ} / \mathrm{yr}$ & 930.5 & 982.7 & $1,622.9$ & $1,637.8$ & 53.6 \\
\hline Energy input for crops & $\mathrm{TJ} / \mathrm{yr}$ & -48.8 & -51.5 & -181.6 & -183.3 & -129.4 \\
\hline Energy for transport & $\mathrm{TJ} / \mathrm{yr}$ & -3.8 & -8.2 & -6.3 & -123.8 & -6.7 \\
\hline Net energy production & $\mathbf{T J} / \mathbf{y r}$ & $1,077.9$ & $1,134.2$ & $1,784.0$ & $1,682.9$ & 203.3 \\
\hline Share covered by biomass & & $1.87 \%$ & $1.97 \%$ & $3.26 \%$ & $3.29 \%$ & $2.67 \%$ \\
\hline \multicolumn{7}{|l|}{ Emission indicator } \\
\hline Avoided emission from electricity & $\mathrm{t} \mathrm{CO}_{2 \mathrm{eq}} / \mathrm{yr}$ & 28,162 & 29,740 & 49,119 & 49,567 & 40,240 \\
\hline Avoided emission from heat & $\mathrm{t} \mathrm{CO}_{2 \mathrm{eq}} / \mathrm{yr}$ & 63,855 & 67,435 & 111,374 & 112,391 & 3,678 \\
\hline Emissions for crops & $\mathrm{t} \mathrm{CO}_{2 \mathrm{eq}} / \mathrm{yr}$ & -6 & -6 & -59 & -59 & -42 \\
\hline Emissions for transport & $\mathrm{t} \mathrm{CO}_{2 \mathrm{eq}} / \mathrm{yr}$ & -271 & -582 & -442 & -969 & -470 \\
\hline Net avoided emissions & t $\mathrm{CO}_{2 \mathrm{eq}} / \mathrm{yr}$ & 91,740 & 96,588 & 159,992 & 160,930 & 43,405 \\
\hline Em reduction wrt 2005 fossil fuel & & $-1.18 \%$ & $-1.24 \%$ & $-2.05 \%$ & $-2.06 \%$ & $-0.56 \%$ \\
\hline $\begin{array}{l}\text { Em reduction wrt } 2005 \text { final } \\
\text { internal consumption }\end{array}$ & & $-1.97 \%$ & $-2.08 \%$ & $-3.44 \%$ & $-3.46 \%$ & $-0.93 \%$ \\
\hline
\end{tabular}

\section{Acknowledgement}

This work has been supported by CRPV (Centro Ricerche Produzioni Vegetali) and by LEAP (Laboratorio Energia Ambiente Piacenza) through the IEE project Renewed (EISAS/EIE/06/162/2006).

\section{References}

[1] EEA-European Environment Agency, How much bioenergy can Europe produce without harming the environment?, Report No 7/2006, 2006.

[2] D. Tilman, R. Socolow, J. A. Foley, J. Hill, E. Larson, L. Lynd, S. Pacala, J. Reilly, T. Searchinger, C. Somerville, et al., Beneficial Biofuels--The Food, Energy, and Environment Trilemma, Science (2009) 325: 270-271.

[3] G. Fiorese, G. Guariso, A GIS-based approach to evaluate biomass potential from energy crops at regional scale, Environmental Modelling \& Software, In Press, Corrected Proof, Available online 7 December 2009, DOI: 10.1016/j.envsoft.2009.11.008.

[4] Z. Drezner, H.W. Hamacher, Facility Location: Applications and Theory, Springer Verlag, Berlin (2001).

[5] M.C. Heller, G.A. Keoleian, M.K. Mann, T.A. Volk, Life cycle energy and environmental benefits of generating electricity from willow biomass, Renewable Energy (2004) 29, 1023-1042.

[6] Lindo. LINDO Systems - Optimization Software: Integer Programming, Linear Programming, Nonlinear Programming, Global Optimization, What'sBest!, 2009.
[7] A. Buscaroli, A. Gagliardi, A. Morini, Censimento e indirizzi di riciclo delle biomasse, studio commissionato dalla Provincia di Ravenna, Università di Bologna, 2007.

[8] W. Righini, "Prospettive alla luce delle normative ed incentivi per le fonti rinnovabili”, in Tecnologie e prospettive della produzione di energia da biomasse, Politecnico di Milano, (2006), 131-144.

[9] G. Fiorese, G. Guariso, A. Polimeni, "Optimizing biogas production: an application to an Italian farming district", in Proc. iEMSs 2008, pp. 1289-1296.

[10] D. Freppaz, R. Minciardi, M. Robba, M. Rovatti, R. Sacile, A. Taramasso, Optimizing forest biomass exploitation for energy supply at a regional level, Biomass and Bioenergy (2004), 26, 15-25.

[11] Terna Spa, 2009. www.terna.it.

[12] Montanari, Ravenna e i mutamenti climatici. Statistiche, $\begin{array}{lll}\text { Provincia di Ravenna, } & \end{array}$ http://www.racine.ra.it/provincia/statistica/archivio.htm.

[13] A.C. Caputo, M. Palumbo, P.M. Pelagagge, F. Scacchia, Economics of biomass energy utilization in combustion and gasification plants: effects of logistic variables, Biomass and Bioenergy (2005) 28, 35-51. 